\title{
AJUSTES MORFOLÓGICOS ASOCIADOS A OBRAS DE CORRECCIÓN HIDROLÓGICA Y DE CONTROL DE LA EROSIÓN EN UN SISTEMA FLUVIAL MEDITERRÁNEO: RÍO CHICO (VÉLEZ RUBIO, ALMERÍA)
}

\section{MORPHOLOGICAL ADJUSTMENTS TO HYDROLOGIC CORRECTION WORKS AND EROSION CONTROL IN A MEDITERRANEAN FLUVIAL SYSTEM: RÍO CHICO (VÉLEZ RUBIO, ALMERÍA)}

\author{
Pedro Pérez Cutillas \\ Universidad de Murcia \\ pedrope@um.es \\ Carmelo Conesa García \\ Universidad de Murcia \\ cconesa@um.es \\ Miguel Sánchez Gonzálvez \\ Universidad de Murcia \\ miguel.sanchez4@um.es
}

Recibido: octubre, 2014.

Versión final aceptada: junio, 2015.

PALABRAS CLAVE: Corrección hidrológica, hidrogeomorfológica, rambla.

KEY WORDS: Hydrological correction, hydromorphological, ephemeral channel.

\section{RESUMEN}

Los sistemas fluviales mediterráneos, caracterizados por precipitaciones irregulares y de gran intensidad, constituyen ambientes de extremada vulnerabilidad. Estos sistemas, ya de por si alterados, se ven afectados por cambios morfológicos generados por actuaciones de origen antrópico, que han ocasionado en las últimas décadas numerosos y graves efectos ambientales. Una evidente muestra de ello se produce en el río Chico, que se ha visto sometido a una intensa alteración hidrológica y morfológica. La construcción de diques y escolleras han sido las obras más utilizadas, aunque no han sido siempre efectivas, generando en muchos casos variaciones en los flujos sedimentarios y en los procesos de erosión. Por el contrario, las obras de menor tamaño presentan una mejor integración en el lecho, actuando mejor y no han provocado grandes alteraciones locales. La ausencia o disminución de estas actuaciones en el cauce dispondría de un mayor espacio fluvial, garantizando la recuperación de sus valores naturales. 


\section{ABSTRACT}

The Mediterranean fluvial systems, characterised by irregular and high intensity rainfall, are extremely vulnerable environments. These natural systems are altered by human activities, causing morphological adjustments and numerous, serious environmental problems in recent decades. A clear example of this is the river Chico, which has been submitted to an intense alteration, both hydrologic and morphologic. Dams and ripraps have been the constructions used most, although they have not always been effective, in many cases generating changes in the sedimentary flows and in the processes of erosion. On the contrary, the smaller-scale works carried out present a better integration in the riverbed, have performed well and have not provoked big local alterations. The absence or decrease of these works in the riverbed would yield a greater fluvial space, guaranteeing the recovery of the natural values. 


\section{INTRODUCCIÓN.}

El carácter torrencial de la vertiente mediterránea española es especialmente acusado en el sureste peninsular, donde se suceden episodios de intensidad pluviométrica concentrada en poco tiempo con largos periodos de aridez (López Bermúdez et al., 1998). Para controlar la inestabilidad de los cauces, desarrollados dentro de este ámbito, se realizan obras de restauración hidrológico-forestal, que pretenden regular los procesos erosivos ralentizando la velocidad de la corriente, potenciando la infiltración de agua en el suelo o proporcionando una retención de los sedimentos movilizados (Conesa García y García Lorenzo, 2007).

La obra estructural más común es el dique de retención o pequeña presa, cuyo principal objetivo es laminar las avenidas y reducir la carga de material sólido durante los episodios torrenciales. Los efectos geomorfológicos de los diques varían según las condiciones ambientales donde se construyen, pero también dependen de los tramos del cauce en los que se instalan. Debido a las alteraciones sufridas por estas obras, se suceden cambios en la competencia de la corriente, que modifican a su vez la geodinámica natural del cauce. Ello implica una adaptación morfológica inmediata o a corto plazo del sistema fluvial, que afecta sobre todo al cauce y sus riberas (Ollero, 2009).

Es conocido que aguas arriba del dique se va produciendo una acumulación progresiva en el lecho por un incremento del nivel de base local (García-Ruiz et al., 2010) y también, aguas abajo aparecen alteraciones geomorfológicas muy marcadas (Brandt, 2000). Con la regulación de los caudales y la reducción de la carga de fondo, el canal se hace más estrecho, profundo y serpenteante (Sundborg, 1956; Csiki y Rhoads, 2010). De igual modo, con la reducción de la pendiente pueden aparecer pequeños canales trenzados (braided) en las cuñas de sedimentos retenidos (Bridge, 1993), que sólo son capaces de persistir en condiciones de aguas bajas ó caudal laminado y terminan desapareciendo tras episodios de avenidas torrenciales.

Se ha constatado que los espacios naturales más frágiles y deteriorados de Europa son los ríos y sus riberas (Tockner y Stanford, 2002). Es evidente, en este sentido, que toda conservación integral del río como ecosistema y corredor ambiental, que garantice la biodiversidad, la protección e interrelaciones de los elementos del sistema y en consecuencia, su calidad ambiental, requiere adoptar medidas orientadas a mantener la dinámica hidrogeomorfológica natural del mismo (Briedley y Fryirs, 2005). Para ello, es necesario mejorar algunos aspectos hidromorfológicos de los cauces y de sus riberas, y definir nuevas líneas de actuación que permitan recuperar la dinámica y la capacidad de regeneración de los sistemas fluviales, fomentando de una manera progresiva su restauración y conservación (VV.AA., 2010).

Habitualmente las labores de restauración de riberas en la cuenca del río Segura suelen ejecutarse por tramos aislados (CHS, 2008), pero a menudo los problemas que se 
intentan subsanar en un tramo dado provienen de otras actuaciones, realizadas aguas arriba o abajo, o en cualquier punto de la cuenca vertiente, que transmiten directa 0 indirectamente sus efectos al tramo en cuestión (Thorne et al., 1996). Un sistema fluvial semiárido es siempre dinámico y complejo, de manera que toda intervención del hombre sobre éste necesita ser planificada dentro de programas de restauración y gestión conjunta a nivel de cuenca.

Debido a la multiplicidad de factores que intervienen en la dinámica natural de barrancos y ramblas, más compleja si cabe cuando se trata de estudiar los efectos de las obras de corrección hidrológico-forestal (Castillo et al., 2001), se hace muy difícil llegar a un análisis completo de su funcionamiento. En general, las actuaciones de restauración hidrológico-forestal llevadas a cabo durante las últimas décadas en la vertiente mediterránea española suelen estar orientadas a la regeneración de la cubierta vegetal, la realización de obras de control hidrológico (Conesa García y García Lorenzo, 2007), o al estudio de los mecanismos generadores de escorrentía (Martín Rosales et al., 1995). De hecho, son numerosos los autores que han trabajado, dentro de este ámbito, sobre temas de restauración hidrológico-forestal, los efectos de las obras de corrección hidrológica y las alteraciones del régimen fluvial. Cabe destacar, por ejemplo, el trabajo de Mintegui et al. (1993) referente a los fundamentos de la restauración hidrológica forestal y sus efectos en cuencas hidrográficas mediterráneas, el de Varela Nieto (1999), que ofrece un detallado inventario de obras de corrección hidrológico-forestal y de variables ambientales asociadas, o el de Bombino et al. (2014) sobre la influencia de los diques en la vegetación de torrentes mediterráneos. Otros trabajos están más enfocados al estudio de la efectividad de los diques de retención de sedimentos y de sus efectos geomorfológicos en cursos de agua semiáridos (Prosser et al., 2002; Boix-Fayos et al., 2007; Zema et al., 2014), o en sistemas fluviales de montaña (García-Ruiz y Puigdefábregas, 1985).

En lo que concierne al río Chico, se ha realizado recientemente un estudio de valoración ambiental (CHS - AYESA, 2010) financiando por la CHS, dentro del programa del Ministerio de Medio Ambiente y Medio Rural y Marino para el desarrollo de la Estrategia Nacional de Restauración de Ríos, cuyo objetivo es la conservación y recuperación del buen estado ecológico de los ríos, en cumplimiento del mandato de la Directiva Marco del Agua (Directiva 2000/60/CE). Como complemento de este informe, en el presente trabajo se analizan los ajustes morfológicos producidos por las obras de corrección hidrológica y de control de la erosión efectuadas en dicho río-rambla. Se intenta con ello ofrecer una visión más amplia de los procesos geomorfológicos que derivan de las citadas actuaciones y poner de evidencia la importancia que tiene su estudio para futuros proyectos de restauración fluvial. 


\section{2. ÁREA DE ESTUDIO Y CARACTERIZACIÓN AMBIENTAL.}

El río Chico drena una subcuenca de $13,23 \mathrm{~km}^{2}$, perteneciente a la cuenca de la rambla de Chirivel (provincia de Almería), forma parte de la cuenca alta del río Guadalentín, tributario principal del río Segura. El curso fluvial objeto de estudio $(4,7 \mathrm{~km})$ comienza aguas abajo de los límites del Parque Natural de Sierra María - Los Vélez, al pie del pico del Maimón (Figura 1), y queda encuadrada entre las coordenadas UTM del Sistema de referencia ETRS89: 579698 - 4170770 y 582153 - 4167610.

Figura 1. Localización de la cuenca del río Chico en el contexto de la cuenca hidrográfica del río Segura. Delimitación de los tramos analizados I (abarrancado de cabecera) y II (río-rambla), cada uno de ellos subdivididos en tres subtramos.

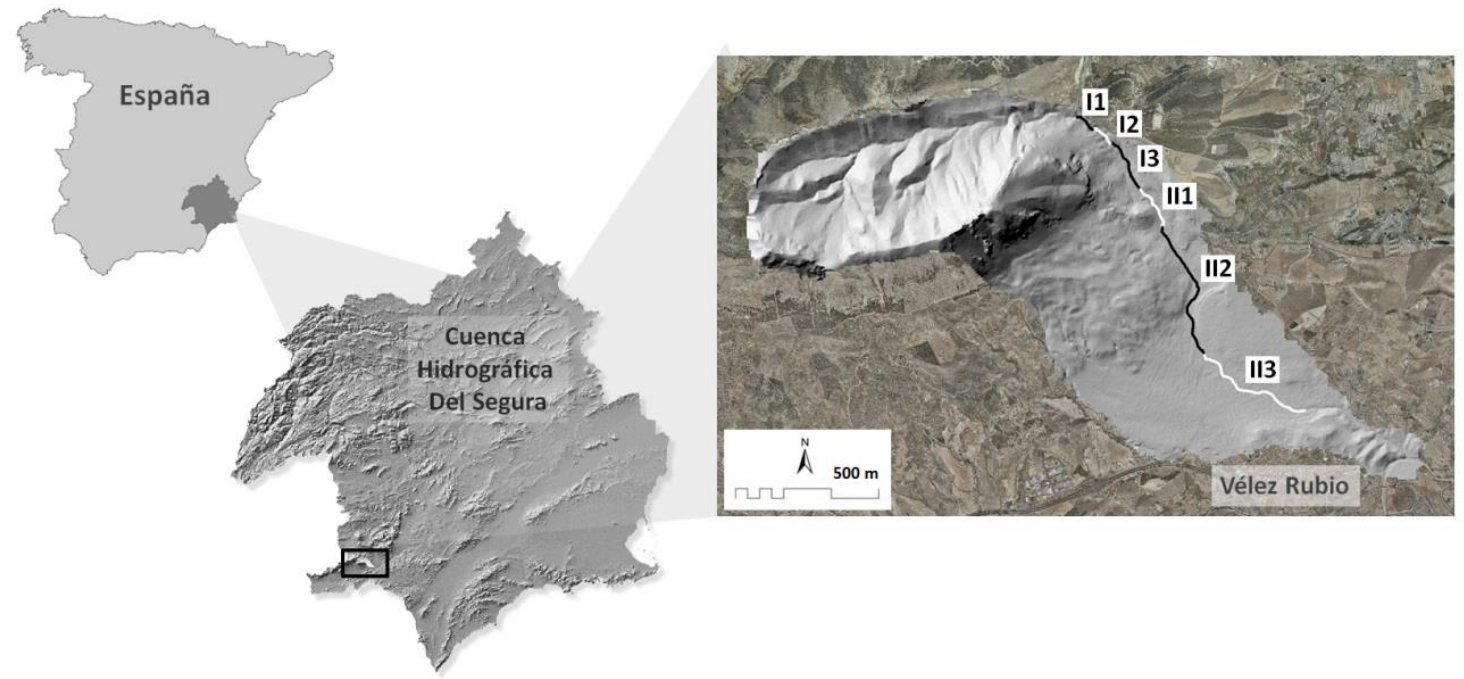

Las características generales de la cuenca del Río Chico están marcadas por la presencia de la Sierra de Maimón, que constituye parte del Parque Natural de la Sierra de MaríaLos Vélez. La altitud media de la cuenca es de 1.100 m., y su pendiente media $14^{\circ}$. Aun siendo una cuenca de tamaño reducido, muestra diferencias topográficas apreciables y una altitud muy variable, entre los 1.731 y $739 \mathrm{~m}$. Como consecuencia de ello, existen zonas con pendientes bastante contrastadas, que comprenden desde terrenos escarpados con fuerte declive $\left(>50^{\circ}\right.$ ) hasta sectores completamente llanos. En general, se distinguen tres unidades de relieve: sector de cabecera, tramo intermedio y tierras bajas. La zona de cabecera, situada al NO de la cuenca, se caracteriza por la presencia de terrenos muy elevados (> $1300 \mathrm{~m}$ de altitud) y pendientes acusadas (> $35^{\circ}$ ). Aquí inicia su cauce, en medio de la Sierra de Maimón, el Barranco de la Cruz del Pinar, asistido por otros barrancos de menor entidad. Esta área ofrece una red de drenaje densa y compleja, formada por multitud de barrancos y barranqueras. La segunda unidad, extendida al pie de la Sierra de Maimón, vierte sus aguas a un único colector principal que recibe el nombre de Rio Chico. El relieve pierde energía y la pendiente del

ISSN: 0212-8594 ISSN-e: 2340-2776.№ DOI: http://dx.doi.org/10.12795/rea.2015.i32.07 
terreno se hace menos acusada. Se trata de una zona de transición compuesta por antiguos niveles de glacis, que tienen especial desarrollo la margen derecha del cauce principal y donde se aprecian los efectos erosivos en dichas terrazas. Finalmente, la parte baja de la cuenca se caracteriza por la presencia de altitudes inferiores a $1000 \mathrm{~m}$, terrenos de pendiente más suave $\left(<5^{\circ}\right)$ y materiales relativamente finos que integran las formaciones distales de los abanicos aluviales procedentes de la sierra de Maimón.

Desde el punto de vista climático, se encuentra en un ámbito mediterráneocontinental, caracterizado por una temperatura media anual de $14,5^{\circ} \mathrm{C}$, una amplitud térmica de 15 a $17{ }^{\circ} \mathrm{C}$ y temperaturas suaves salvo en invierno. La pluviometría es escasa ( $\approx 400 \mathrm{~mm} / \mathrm{año})$, agravada por su torrencialidad y fuerte irregularidad estacional, presentando valores máximos de precipitación que se concentran en otoño y primavera (INM, 2014).

\section{MATERIAL Y MÉTODOS.}

Los tramos de estudio han sido definidos a partir de ortoimágenes PNOA (2009 - 2011) y con ayuda de trabajo de campo. Para este análisis, la zona en estudio del río Chico ha sido dividido en dos tramos de ubicación y morfología bien diferente (Figura 1): I. tramo abarrancado de cabecera y II. tramo de río-rambla. El tramo de cabecera muestra un cauce en forma de $\mathrm{V}$ y se compone de tres subtramos definidos en función de su posición, grado de abarrancamiento y obras de corrección hidrológica, mientras que el tramo de río-rambla presenta un cauce fluvial algo menos encajado, con sección en artesa y gran movilidad de la carga de fondo. Este último también consta de tres subtramos, diferenciados por el tipo de actuación llevada a cabo sobre el cauce y sus principales efectos morfológicos: II1. Subtramo alto, dominado por protecciones del margen por escolleras de piedra y la alternancia de pequeñas cuñas sedimentarias y pozas de erosión, asociada a la construcción de traviesas y diques de retención de sedimentos; II.2. Subtramo medio, con márgenes recrecidos mediante motas de tierra y una intensa ocupación humana del espacio fluvial, que conlleva graves problemas de incisión; y II.3. Subtramo bajo, totalmente encauzado, con muros de mampostería hidráulica, sometido a procesos de acreción sedimentaria vertical en el lecho (Figura 2).

Los trabajos de campo consistieron principalmente en la descripción y medición de las obras transversales y longitudinales existentes en el cauce, y en el reconocimiento y delimitación de las formas de alteración del cauce. Para cada una de estas geoformas se ha realizado un seguimiento de sus características geométricas y estado de evolución, de acuerdo con la distancia a la estructura en cuestión, para así determinar el grado de influencia de ésta. La localización de las estructuras instaladas en el cauce y la delimitación de las consiguientes formas del lecho alteradas se han llevado a cabo mediante un receptor GNSS. Una vez digitalizados los contornos correspondientes a dichas formas, así como los límites de los márgenes que han sufrido erosión lateral y los perímetros de obstáculos para la corriente (edificaciones, carreteras y caminos

ISSN: 0212-8594 ISSN-e: 2340-2776.№ DOI: http://dx.doi.org/10.12795/rea.2015.i32.07 
Figura 2. Secciones transversales del cauce en los tramos I3 (a), II1 (b), II2 (c) y II3 (d) del río Chico y su localización en la cuenca. Fuente de las secciones: CHS -AYESA (2010).
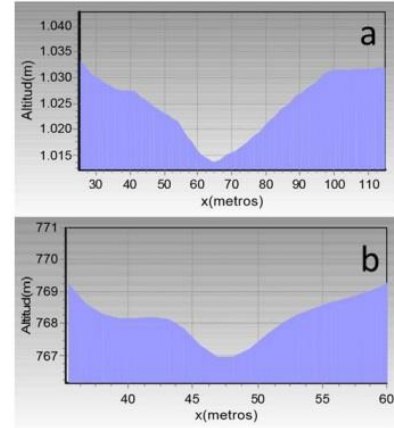

b

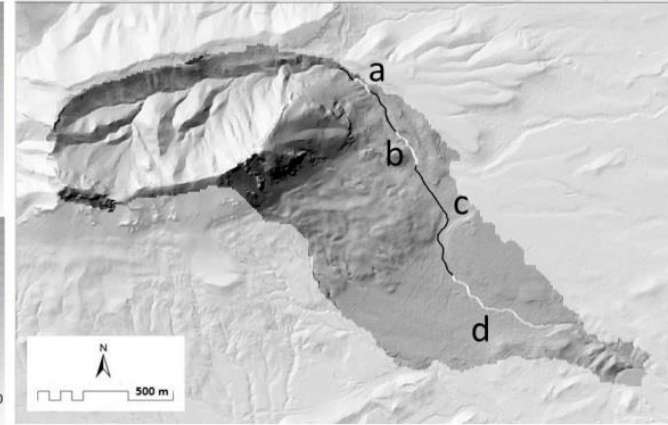

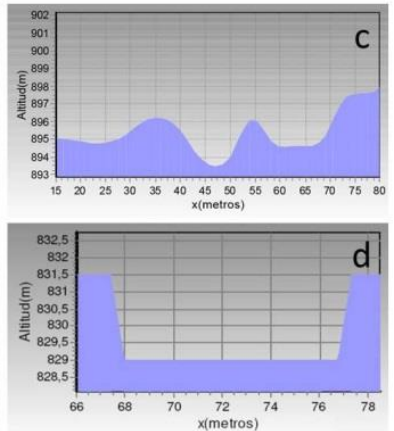

elevados) o de determinadas formas artificiales que afectan a los flujos de avenida (motas, encauzamiento, etc.), se procede a su análisis espacial mediante SIG. Se obtienen así los sectores y tramos de cauce que presentan diferentes tipos de ajustes morfológicos (incisión, erosión lateral, socavamiento basal, etc.), en relación con la ubicación y las características de cada estructura. Asimismo, se ha utilizado información altimétrica suministrada por un Modelo Digital del Terreno de la cuenca (CNIG, 2014), y para completar el análisis se ha empleado los servicios WMS de la IDE Andalucía (2014), que aporta datos ambientales y ortoimágenes de diferentes periodos válidos para las labores de fotointerpretación realizadas.

\section{PRINCIPALES ACTUACIONES Y EFECTOS GEOMORFOLÓGICOS.}

Son muchas y variadas las actuaciones que se han llevado a cabo recientemente en el río Chico. La mayoría de ellas son estructuras transversales de retención de sedimento (diques y traviesas), que tienen por finalidad reducir la pendiente del lecho y, con ello, la velocidad de la corriente, el transporte de fondo y su potencial erosivo. Las obras longitudinales (escolleras), principalmente diseñadas para la protección de los márgenes, también aparecen muy extendidas a lo largo de este curso fluvial. En las tablas 1 y 2 se muestran los principales efectos geomorfológicos producidos por las actuaciones realizadas en los tramos de barranco y de río-rambla respectivamente.

Las estructuras más duras son las escolleras de bloques cementados, cuya resistencia mecánica a la corriente es muy superior a la que presentan los materiales aluviales de los márgenes, y, por tanto, desplazan las formas de erosión inmediatamente aguas arriba y abajo de ellas. No menos importantes son los efectos provocados por los diques de mampostería y de gaviones (cestas de forma prismática rectangular con malla de alambre, rellenas de bloques de piedra, a veces extraídos del mismo lecho torrencial), tales como aterrazamientos, pozas de erosión, descalce de sus estribos laterales, incisión progresiva del lecho, etc. A este tipo de escolleras suceden aguas abajo, dentro del tramo abarrancado, las escolleras colocadas, construidas a lo largo de márgenes externos curvos mediante bloques de roca caliza. Su efecto más visible es

ISSN: 0212-8594 ISSN-e: 2340-2776.№ DOI: http://dx.doi.org/10.12795/rea.2015.i32.07 
la formación de profundos surcos locales en las zonas de contacto con el talud natural del margen. Tales actuaciones continúan estando presentes aguas abajo en el tramo de río-rambla (II), unidas a otras que suponen la ocupación humana del llano de inundación, e incluso del cauce, y la modificación de la sección transversal del sistema fluvial global. Entre estas últimas, destaca, por ejemplo, la construcción de motas en el tramo medio (II2) y el encauzamiento del tramo inferior (II3) (Tabla 2). Ambas actuaciones impiden que el río gestione de forma adecuada su propio espacio, perdiendo gran parte de sus funciones naturales y de su continuidad tanto lateral como longitudinal.

Aguas abajo del tramo de motas se hacen frecuentes los segmentos de escollera, que no solo protegen las partes bajas del margen, sino que también se emplean como basamento de otras obras de contención o como refuerzo y protección de carreteras y caminos próximos al margen. Existen además escolleras que conforman una segunda línea de defensa, que protegen el cauce de avenida. Pero los efectos visuales y geomorfológicos más significativos dentro de este tramo se deben al encauzamiento final.

A pesar de haber aumentado inicialmente la pendiente del cauce, de 3 a 3,7 \%, y la velocidad de la corriente, los procesos de acreción sedimentaria vertical del lecho dominan sobre los de erosión lineal. Todas estas infraestructuras combinan sus efectos con otras más puntuales (edificios, carreteras, acequias, etc.) que invaden el espacio fluvial, provocando una profunda alteración morfológica del cauce, la desnaturalización de sus orillas y la interrupción de la continuidad longitudinal y transversal de sus ecosistemas.

\subsection{Tramo de barranco (I)}

El tramo de cabecera (I) (1.137 m de longitud) lo constituye un barranco de fuerte pendiente y perfil en forma de $\mathrm{V}$, profundamente entallado en el sustrato rocoso. Los márgenes son escarpados y presentan escasa vegetación, mientras que en el lecho alternan sectores de roca caliza desnuda con depósitos de material granular grueso y muy grueso. El agua de escorrentía sólo aflora localmente procedente de pequeñas surgencias en el contacto de dichos materiales. A pesar de tratarse de un tramo corto, las distintas actuaciones antrópicas realizadas en el mismo, con sus consiguientes efectos geomorfológicos, permite distinguir tres subtramos:

\subsubsection{Subtramo alto (I1)}

El primer subtramo comienza en un afloramiento de agua, coincidiendo con la zona de separación del Barranco de la Cruz y el Rio Chico. Esta surgencia aparece interrumpida por un camino que ha sido protegido por muros de mampostería contra la erosión fluvial. Aun así, la existencia de un desnivel de $2 \mathrm{~m}$ puede provocar en época de 
Pedro Pérez Cutillas, Carmelo Conesa García, Miguel Sánchez Gonzálvez

Ajustes morfológicos asociados a obras de corrección hidrológica y de control de la erosión en un sistema fluvial mediterráneo: Río Chico (Vélez Rubio, Almería).

Tabla 1. Principales efectos geomorfológicos asociados a diferentes tipos de actuación en los tramos de barranco (I).

\begin{tabular}{|c|c|c|}
\hline \multicolumn{3}{|l|}{ BARRANCO } \\
\hline Subtramo & Tipo de infraestructura & Tipo de efecto \\
\hline I1 & $\begin{array}{l}\text { Camino reforzado por } \\
\text { mampostería }\end{array}$ & $\begin{array}{l}\text { Ruptura de pendiente } \\
\text { Incisión en la base }\end{array}$ \\
\hline I1 & Escollera central & $\begin{array}{l}\text { Incisión lateral } \\
\text { Incisión en la base }\end{array}$ \\
\hline 12 & 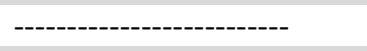 & ----------------------------- \\
\hline 13 & Dique de gaviones & $\begin{array}{l}\text { Colmatación del dique } \\
\text { Reducción de la pendiente y ruptura de continuidad de la misma } \\
\text { Erosión y descalce en la base }\end{array}$ \\
\hline 13 & Escollera lateral & $\begin{array}{l}\text { Erosión margen opuesta } \\
\text { Desconexión margen-lecho }\end{array}$ \\
\hline 13 & Dique de mampostería & $\begin{array}{l}\text { Colmatación del dique } \\
\text { Reducción de la pendiente y ruptura de continuidad de la misma } \\
\text { Erosión y descalce en la base } \\
\text { Acorazamiento aguas abajo }\end{array}$ \\
\hline 13 & Dique de gaviones & $\begin{array}{l}\text { Colmatación del dique } \\
\text { Erosión lateral } \\
\text { Erosión remontante } \\
\text { Incisión en la base }\end{array}$ \\
\hline 13 & Escollera lateral & $\begin{array}{l}\text { Acorazamiento en margen opuesta } \\
\text { Desconexión margen-lecho }\end{array}$ \\
\hline 13 & $\begin{array}{l}\text { Traviesas longitudinales } \\
\text { de gaviones }\end{array}$ & $\begin{array}{l}\text { Buena integración de la primera hilera de gaviones } \\
\text { Desmantelamiento de la segunda hilera de gaviones } \\
\text { Aporte de rocas de la estructura al lecho }\end{array}$ \\
\hline 13 & $\begin{array}{l}\text { Dique de gaviones } \\
\text { reforzado con cemento }\end{array}$ & $\begin{array}{l}\text { Colmatación del dique } \\
\text { Reducción de la pendiente y ruptura de continuidad de la misma } \\
\text { Erosión y descalce en la base } \\
\text { Incisión aguas abajo }\end{array}$ \\
\hline 13 & Escollera lateral & $\begin{array}{l}\text { Incisión vertical al inicio } \\
\text { Desmantelamiento puntual } \\
\text { Erosión margen opuesta } \\
\text { Erosión lateral aguas abajo de la obra } \\
\text { Desconexión margen-lecho }\end{array}$ \\
\hline
\end{tabular}

avenidas un fuerte proceso erosivo en la base. A lo largo de todo este subtramo, la sección transversal resulta muy variable e irregular, al igual que el lecho fluvial, compuesto por estrechos canales que sortean grandes bloques de roca. La sucesión de resaltos y pozas está muy presente en este primer subtramo, y, aunque con tamaño reducido, se aprecian diversas incisiones en el material cohesivo no cubierto por bloques. Durante las avenidas se advierten importantes cambios longitudinales en la geometría hidráulica, que hacen variar también la velocidad de la corriente en distancias relativamente cortas (González, M. y García, D., 1998). En la zona media de este tramo de barranco la inestabilidad de parte de la ladera afecta la dinámica morfológica del margen derecho del río. A dicho estado inestable contribuye la combinación de procesos de deslizamiento traslacional (Translational slide) (Fuchu et al., 1999) con la presencia de profundos surcos. La línea de ruptura de esta ladera se 
Tabla 2. Principales efectos geomorfológicos asociados a diferentes tipos de actuación en los tramos de río-rambla (II).

\begin{tabular}{|c|c|c|}
\hline \multicolumn{3}{|c|}{ RÍO-RAMBLA } \\
\hline Subtramo & Tipo de infraestructura & Tipo de efecto \\
\hline II1 & Camino reforzado & $\begin{array}{l}\text { Ruptura de pendiente } \\
\text { Erosión en la base } \\
\text { Erosión lateral } \\
\text { Acorazamiento aguas abajo }\end{array}$ \\
\hline II1 & Escollera lateral & $\begin{array}{l}\text { Vaciado de material entre escollera y camino } \\
\text { Erosión margen opuesta } \\
\text { Desconexión margen-lecho }\end{array}$ \\
\hline II1 & Dique de hormigón & $\begin{array}{l}\text { Ruptura de pendiente } \\
\text { Buena integración por abundancia de vegetación }\end{array}$ \\
\hline II1 & Secuencia de albarradas & Estabilización de pendiente \\
\hline 112 & Camino reforzado & $\begin{array}{l}\text { Ruptura de pendiente } \\
\text { Erosión en la base }\end{array}$ \\
\hline 112 & Escolleras laterales & $\begin{array}{l}\text { Incisión del lecho } \\
\text { Desconexión con llanura de inundación }\end{array}$ \\
\hline 112 & Motas de tierra & $\begin{array}{l}\text { Alternancia de rápidos y pozas } \\
\text { Desconexión con llanura de inundación }\end{array}$ \\
\hline 112 & Albarrada reforzada & $\begin{array}{l}\text { Estabilidad del lecho aguas arriba } \\
\text { Erosión y descalce en la base }\end{array}$ \\
\hline 112 & Escollera lateral & 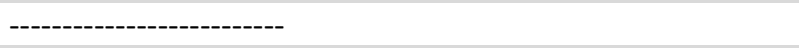 \\
\hline 112 & Molino & Sedimentación \\
\hline 113 & Canalización del río & $\begin{array}{l}\text { Desconexión con llanura de inundación } \\
\text { Cambios en sus niveles freáticos y régimen de humedad } \\
\text { edáfica } \\
\text { Acreción sedimentaria vertical } \\
\text { Erosión en la base de los muros } \\
\text { Erosión al término de la canalización }\end{array}$ \\
\hline II3 & Traviesas & Reducción de pendiente \\
\hline
\end{tabular}

produce a escasos metros del camino asfaltado que discurre junto al río, llegando a alcanzar un poste de suministro eléctrico cuyos cimientos han sufrido un importante descalce y ponen de evidencia claramente la rápida evolución del fenómeno (Figura 4a). En el margen izquierdo, por el contario, se observa una cierta aportación de materiales finos procedentes de la ladera, que terminan alimentando pequeñas barras laterales.

El caudal permanente de agua se limita aquí a un pequeño curso, de una anchura no superior a $0,5 \mathrm{~m}$. Se trata de un flujo rugoso, muy poco profundo, parcialmente interrumpido por grandes bloques de roca dispersos, adaptado a un cauce estrecho de gran irregularidad topográfica. La obra más representativa, dentro de este tramo, es una escollera de protección del lecho construida del pie del desagüe de la carretera A317 (Figura 4b). Como principal efecto destaca la formación de un profundo surco en el borde izquierdo de esta obra, consecuencia directa de un neto cambio lateral en la naturaleza física de los materiales que componen la estructura (bloques de piedra cementados) y el margen del cauce (limos, arenas y gravas). Otra alteración significativa viene impuesta por la abundancia de vertidos antrópicos al cauce. Ello,

ISSN: 0212-8594 ISSN-e: 2340-2776.N№ DOI: http://dx.doi.org/10.12795/rea.2015.i32.07 
Figura 4. (a) Deslizamiento de ladera que afecta al margen derecho del cauce. (b) Incisión lateral en la parte superior de la escollera construida en el subtramo I1.

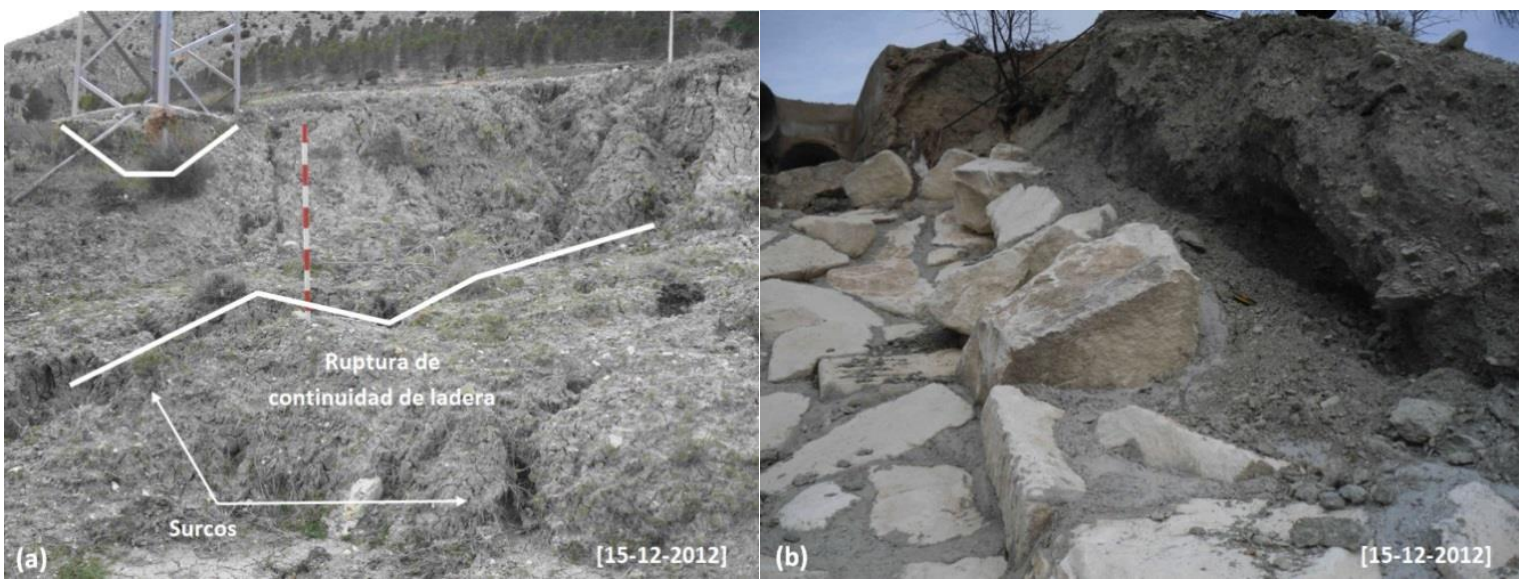

\subsubsection{Subtramo medio (12)}

Este subtramo abarrancado se caracteriza por un claro perfil topográfico en ' $\mathrm{V}$ ' y una pendiente del 3 a $5 \%$. El cauce se encuentra confinado en todo su recorrido, con intercalación de grandes bloques desprendidos de las laderas, que obstaculizan la corriente y limitan su anchura máxima a $3 \mathrm{~m}$ en régimen de aguas ordinarias. Las laderas experimentan aquí procesos de acarcavamiento, especialmente acusados en la vertiente derecha, atribuibles a los cambios de uso del suelo, a la escasa cubierta vegetal presente en márgenes y laderas, y a la naturaleza blanda de los materiales (CHS - AYESA, 2010). La margen izquierda sufre, en cambio, procesos de deslizamiento rotacional, de menor magnitud y mayor extensión que los constatados en el subtramo 11. La alta energía que confiere la verticalidad de estas laderas a las aguas superficiales acelera los procesos erosivos, generando importantes depósitos locales en el interior del cauce que hacen variar la velocidad y trayectoria del flujo. A partir del estrechamiento que suponen estas obstrucciones sedimentarias locales, el cauce va acomodándose a las nuevas condiciones topográficas impuestas por el relieve estructural. La anchura de la sección transversal del cauce aumenta ligeramente conforme el barranco discurre por el frente montañoso, y el escaso caudal que circula por el lecho se bifurca en pequeños cursos intermitentes, algunos de los cuales desaparecen por infiltración, mientras que otros alimentan charcas y pozas en el lecho.

\subsubsection{Subtramo inferior (I3)}

El último subtramo de la zona de cabecera comienza a partir del primer dique (Dq1) del río, construido en el año 2000. Se trata de una estructura transversal de gaviones, compuestos en este caso por bloques de roca extraídos en áreas próximas al lugar de instalación (Conesa García y García Lorenzo, 2007). Inmediatamente aguas abajo del dique tiene lugar un intenso excavado del lecho por causa del resalto hidráulico que

ISSN: 0212-8594 ISSN-e: 2340-2776.No DOI: http://dx.doi.org/10.12795/rea.2015.i32.07

REA 32 (2015):151-176

http://editorial.us.es/es/revista-de-estudios-andaluces 
provoca la estructura. Se forma aquí una gran poza de erosión que pone al descubierto la cimentación del dique (Figura 5a). A ello se une el efecto de la rotura del cuenco amortiguador, que ha intensificado la acción erosiva de las aguas de avenida y, por ende, el lavado superficial del material granular del lecho. Aguas abajo, una escollera de piedra seca recubre el margen derecho desde este primer dique (Dq1) hasta el siguiente (Dq2). La obra se halla en buen estado y escasamente cubierta de vegetación. La protección de dicho margen impide su erosión y por tanto su aportación de sedimentos a la corriente. Como consecuencia, se produce un déficit local en la carga sedimentaria y un incremento de la erosión neta del fondo del cauce. El resultado es un lecho granular fuertemente acorazado compuesto por partículas gruesas (gravas, cantos y bloques) (Figura 5b), que permanecen in situ tras un proceso de transporte selectivo. Ambos diques, actualmente colmatados, han hecho reducir la pendiente longitudinal del cauce más del $2 \%$ y aun así ésta no ha recuperado todavía su estado de equilibrio.

Efectos geomorfológicos más notorios se observan en el tercer dique del tramo (Dq3), donde las aguas de escorrentía torrencial han ido socavando el margen derecho del cauce en la zona adyacente a la obra. Debido al carácter deleznable de los materiales que forman este margen y entran en contacto con el anclaje derecho del citado dique, también de gaviones, la corriente tiende a erosionar con mayor facilidad en dicha línea de contacto creando un profundo surco que termina por desanclar la estructura. Resulta patente la destrucción parcial que ha sufrido la terraza aluvial inferior de este margen por causa de la erosión lateral de la corriente. Ésta es particularmente apreciable cuando finaliza el revestimiento con escollera, ya que el agua encuentra a partir de aquí materiales más erosionables sobre los que descargar la energía que no ha podido gastar erosionando el margen protegido inmediatamente aguas arriba del dique Dq3 (Figura 5c). Por otro lado, la destrucción final de la estructura transversal, asociada a la fuerte erosión lateral que han ejercido las aguas de avenida desde su instalación, ha dado origen a una erosión remontante sobre su propia cuña de sedimentos retenidos. Tal hecho no hace sino aumentar la inestabilidad geomorfológica del lecho aguas abajo. Es comprensible que bajo estas circunstancias se incremente en dicha dirección, de forma brusca, el aporte de sedimentos de tamaño grueso. Incluso, durante grandes avenidas, pueden producirse avalanchas súbitas con ingentes cantidades de material detrítico arrastrado a modo de debrisflows.

La instalación de otra escollera, aguas abajo del dique, reduce localmente la erosión lateral del margen derecho, pero se muestra más vulnerable que la anterior, al tratarse de una estructura "más blanda", integrada por bloques semienterrados en la ladera. No obstante, la acción erosiva afecta su parte inicial, más próxima al dique desmantelado y, por tanto, más expuesta al choque frontal de la corriente. Aguas abajo, todavía se observa un lecho fuertemente acorazado, sobre todo en su parte izquierda, aunque el transporte de sedimentos en régimen natural ha sido ya restablecido tras la rotura del citado dique. 
La última obra transversal que aparece en este primer tramo es otro dique de gaviones reforzado con mortero tanto en la parte superior como en la base. Se encuentra en un estado deteriorado, y los efectos más significativos son el desmantelamiento que sufre en la base y la incisión provocada aguas abajo por la interrupción del flujo sedimentario. El surco (scour hole) generado al pie del dique se debe a la acción combinada de la escorrentía superficial y de la infiltración del agua bajo la obra a través de conductos internos (pipes). El canal resultante de este proceso de incisión configura un nuevo cauce para la circulación de aguas altas ordinarias (bankfull), encajado en el lecho antiguo, anterior a la construcción del dique (Figura $5 \mathrm{~d}$ ). A medida que este nuevo canal se aleja de la estructura pierde profundidad y gana anchura hasta difuminarse en el lecho mayor en un punto cuya cota se mantiene estable. La pendiente longitudinal modificada logra así un nuevo estado de equilibrio y estabilidad. Unos metros más abajo, la erosión fluvial incide sobre la base de varias terrazas agrícolas ubicadas en la margen derecha, liberando sus sedimentos y generando un pequeño abanico aluvial en el lecho del cauce sobre el que incide el nuevo canal "bankfull". La erosión de la base de este margen derecho se da en un sector situado frente al lugar en que termina la obra de escollera del margen opuesto, hecho que puede explicarse por una redistribución de las velocidades (sobre todo secundarias) con una mayor concentración de energía en torno al centro y al margen menos resistente. En su extremo final el tramo se hace rectilíneo y favorece el desarrollo de una extensa barra aluvial central, que bifurca el flujo hacia los márgenes.

\subsection{Tramo de río-rambla (II)}

\subsubsection{Tramo alto dotado de diques y escolleras (III)}

El río-rambla se inicia con un tramo (II1), de menor longitud que el resto (515 m), que parte del cruce de un camino asfaltado con el río a la salida del frente montañoso. A partir de aquí cambia el tipo de ajustes morfológicos del cauce, como consecuencia de una dinámica fluvial distinta asociada a la interacción de las nuevas condiciones impuestas por el flujo, la geometría hidráulica del cauce y las obras realizadas en el mismo. El primer cambio observado lo constituye una brusca ruptura de pendiente, marcada por un salto de 3,5 m inmediatamente aguas abajo de la citada intersección carretera-río rambla. El cauce presenta aquí claros rasgos de acorazamiento estático granular en el lecho y de erosión diferencial en los márgenes. Este último proceso aparece intensificado por la desigual resistencia que ofrecen frente a la erosión lateral ambos márgenes: el izquierdo, de curvatura cóncava, lo componen depósitos de ladera (coluviones) y apenas dispone de una pequeña estructura de protección bajo el paso de la carretera, mientras que el derecho, convexo e interior, se halla recubierto por unaescollera de piedra seca más extensa, bien anclada en su base. La estructura que protege de la erosión al margen izquierdo, sobre el que discurre la carretera vecinal, está formada por grandes bloques de piedra con una leve pendiente sobre una base de hormigón. Debido a la fuerte energía desarrollada por las aguas de avenida en este margen externo, cóncavo, la erosión lateral ha producido un zapado en la obra que la 
Figura 5. (a) Erosión local al pie del dique Dq1; (b) Acorazamiento estático granular del lecho entre los diques Dq1 y Dq2; (c) Erosión lateral con socavamiento y destrucción del dique Dq3; (d) Incisión y encajamiento del lecho aguas abajo del dique Dq4.
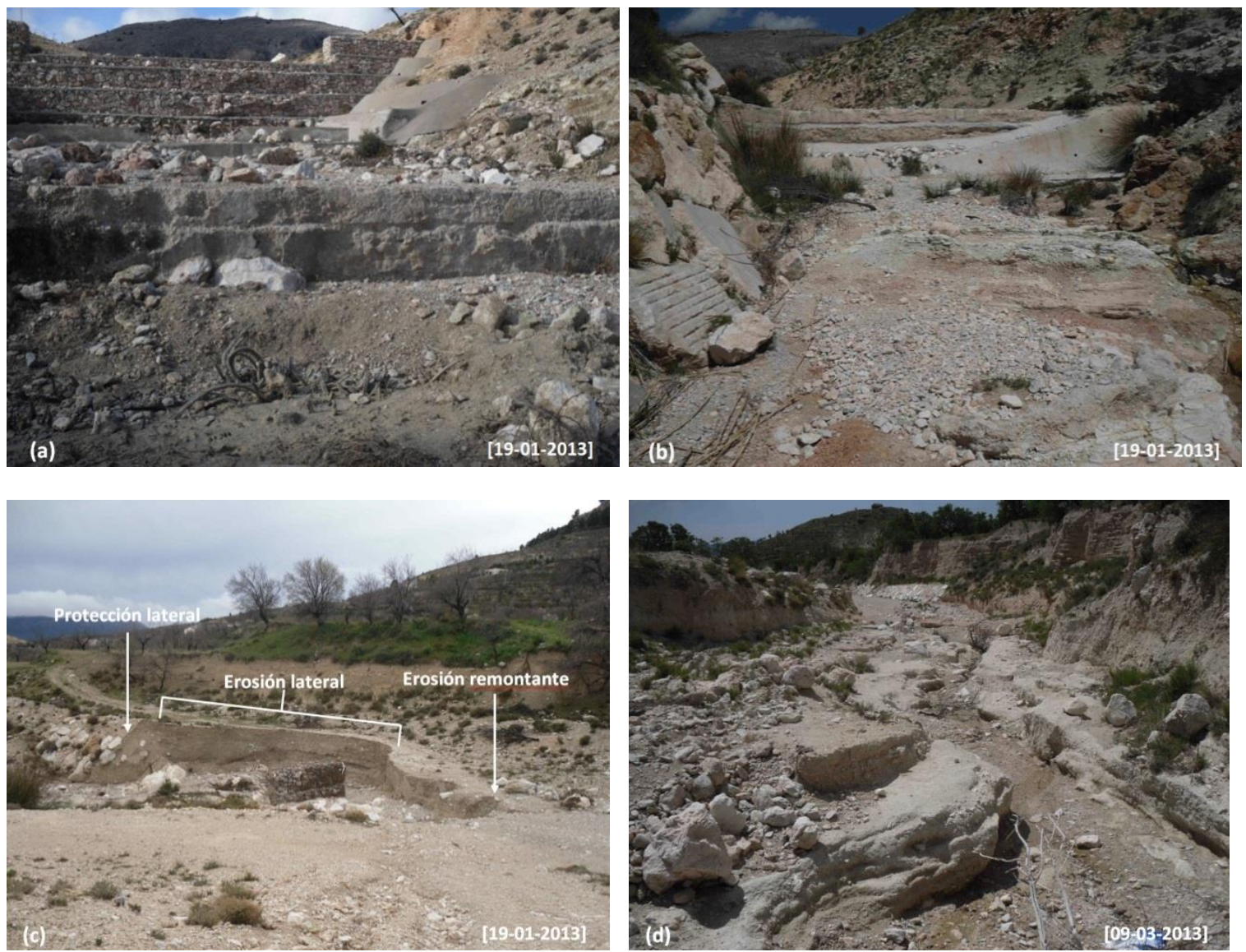

deja al descubierto (Figura 6a). El retroceso del margen y la profundidad de socavado bajo la estructura, medidos sobre el terreno, son de 1 y $2 \mathrm{~m}$ respectivamente. De seguir avanzando dicho proceso puede terminar poniendo en peligro el estado de la carretera y, por tanto, el tráfico de vehículos. La única medida complementaria adoptada para mitigar la erosión en este punto ha consistido en el volcado de tierra extraída de la propia ladera (Figura 6b). Tal actuación no es nada adecuada, ya que se trata de materiales sueltos expuestos a las corrientes de avenida, que pueden ser fácilmente arrastrados, aumentando puntualmente la carga solida del caudal y dejando de nuevo al descubierto el margen erosionado.

Efectos similares han sido ya puestos de manifiesto por Conesa García y García Lorenzo (2011) en cruces de carreteras con ramblas de la franja litoral sur de la Región de Murcia. Según estos autores, determinadas obras de cimentación de las vías de comunicación suelen provocar al pie de las mismas, aguas abajo, pozas y surcos de erosión local, especialmente significativos en cauces con fuerte pendiente, creando

ISSN: 0212-8594 ISSN-e: 2340-2776.№ DOI: http://dx.doi.org/10.12795/rea.2015.i32.07 
Figura 6. (a) Erosión lateral en la zona de contacto de la estructura de protección de la carretera Vélez Blanco-Vélez Rubio y los materiales aluviales del margen; (b) Volcado de tierra extraída del talud superior sobre la zona socavada por la erosión fluvial.
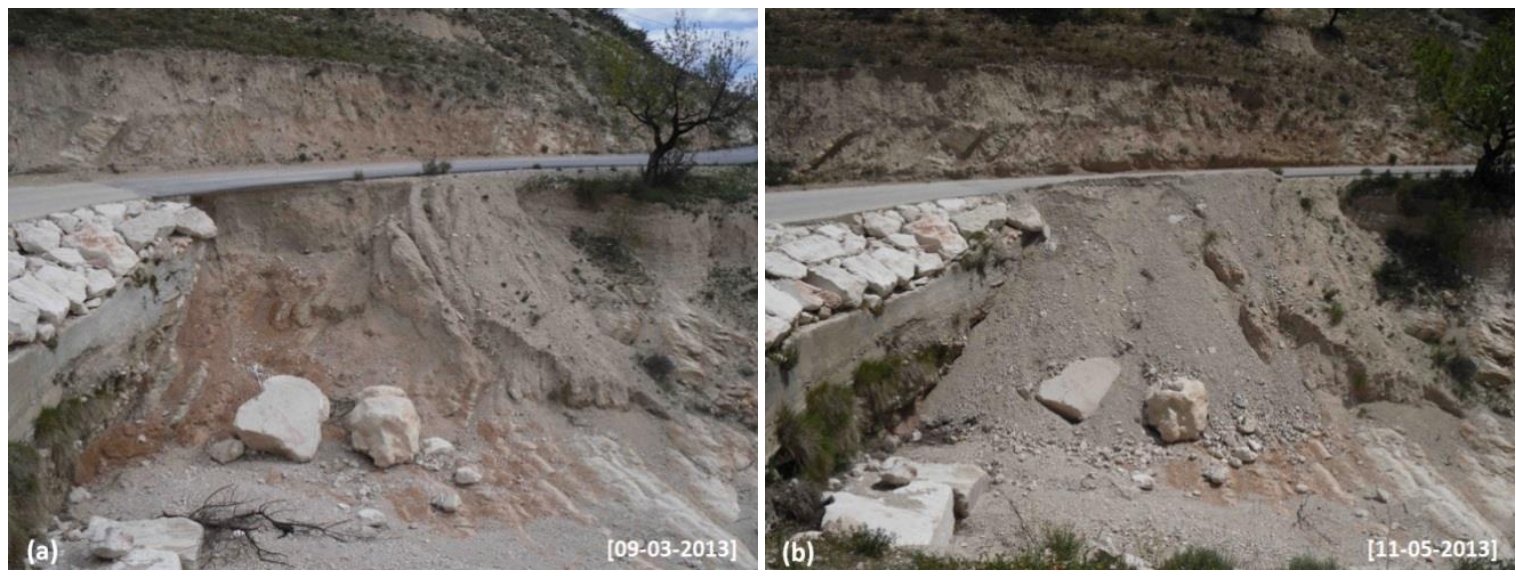

Figura 7. Ejemplo de margen compuesto de materiales poco cohesivos que favorece el ensanchamiento del cauce en los sectores no protegidos con escolleras del tramo II1:

(a) socavado basal, y (b) desmoronamiento.

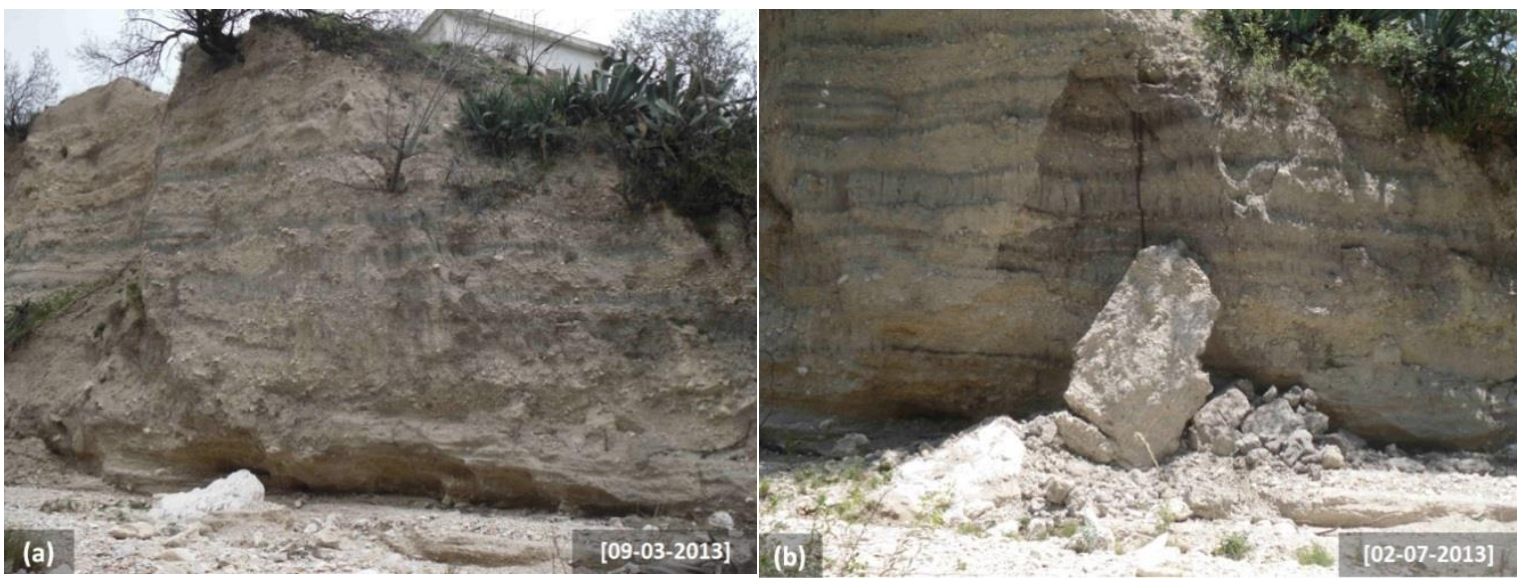

grandes resaltos hidráulicos, que pueden acabar desestabilizándolas e incluso destruirlas.

La parte derecha de la estructura también se halla afectada, pero la escollera que protege este margen se conserva mejor y muestra una mayor estabilidad frente al potencial erosivo de la corriente. En este caso, la acción combinada del lavado superficial de las partículas del lecho y la erosión diferencial en las zonas de contacto de la escollera con los depósitos aluviales y de ladera ha socavado la estructura despegándola de la base hasta originar una oquedad de más de un metro de

ISSN: 0212-8594 ISSN-e: 2340-2776.No DOI: http://dx.doi.org/10.12795/rea.2015.i32.07 
profundidad sobre la que los bloques de roca forman un voladizo inestable. A escasa distancia aguas abajo (apenas $50 \mathrm{~m}$ ) existe otra ruptura de pendiente ocasionada por la erosión local que genera otro dique de hormigón. Aunque algo deteriorada, esta estructura ha sido capaz de completar su función como presa de retención de sedimentos, hallándose en la actualidad colmatada y cubierta por una densa vegetación arbustiva. A pesar de ello, la alta velocidad y energía alcanzada por las corrientes de avenida en este tramo le confieren un elevado poder erosivo aguas abajo del dique, lo que, unido al carácter deleznable de los materiales finos (limos y arenas, con intercalaciones de clastos) que componen ambos márgenes, ha contribuido al ensanchamiento del cauce. La fragilidad de dichos márgenes queda puesta de manifiesto por su extraordinaria dinámica morfológica. La vulnerabilidad físicomecánica de sus materiales, afectados por diversas grietas de tensión, así como la alternancia de capas con textura fina (franco-limosa) y algo más gruesa que configuran diferentes niveles de humectación, restan cohesión y estabilidad al conjunto. Las aguas que esporádicamente circulan por el cauce, y sobre todo las más claras tras quedar retenido su sedimento en las presas, encuentran una relativa facilidad para socavar este tipo de margen, a menudo vertical. Ello conlleva al desencadenamiento de caídas o desplomes de material (Figura 7a y 7b), cuyas partículas, una vez sueltas, se suman a la carga sedimentaria procedente de tramos superiores.

A continuación, aguas abajo, se suceden una serie de traviesas o albarradas, estructuras transversales de pequeña altura que terminan integrándose muy bien en el cauce, en contraste con los diques de mampostería u hormigón armado que les preceden, considerados obras más "duras" y de mayor impacto geomorfológico. Al finalizar estas obras, el cauce es atravesado por otros dos caminos rurales que dan acceso a viviendas ubicadas cerca del río; en el trayecto entre ambos aparecen dispersos grandes troncos de álamo que obstruyen parcialmente la corriente en condiciones de aguas bajas o pueden ser arrastrados en época de fuertes avenidas.

\subsubsection{Tramo medio acondicionado con motas (II2)}

Con una longitud de $1.570 \mathrm{~m}$, este tramo comienza confinado por escolleras a ambos lados del cauce. Debido a estas obras y a una serie de motas dispuestas en la parte inicial del tramo, se ha producido un aislamiento de la llanura de inundación, que le hacer perder parcialmente su función de laminación en fases de desbordamiento. El perfil de la sección transversal del cauce adquiere forma de artesa (Figura 8a) y el fondo pasa a tener una superficie horizontal rugosa, disecada en determinados sectores por fenómenos de fuerte incisión en el lecho. Aguas abajo el lecho del cauce es atravesado por un camino rural utilizado como paso de vehículos, lo que causa la compactación del terreno y obliga al pequeño curso de agua a discurrir por la orilla del margen derecho. Una escollera en buen estado, situada junto al camino, protege la parte superior del cauce de aguas altas en un margen cóncavo claramente expuesto a la acción erosiva de grandes avenidas (Figura 8b). 
Figura 8. (a) Inicio del tramo II2 caracterizado por una sección en artesa y el recrecimiento del cauce con motas de tierra; (b). Margen cóncavo confinado por el trazado de un camino de tierra compactada y la protección de una escollera (tramo II2).

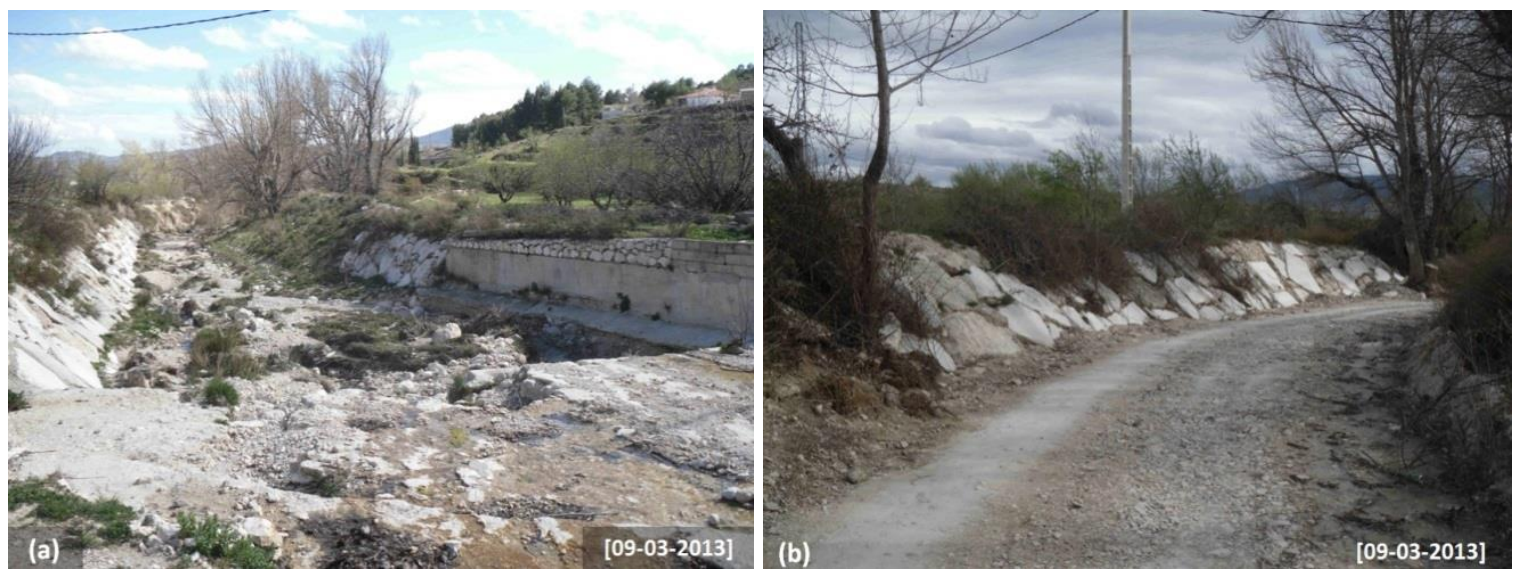

Más abajo aparece un camino que invade el lecho, desviando de nuevo la corriente de estiaje hacia la izquierda, siendo, no obstante, susceptible de ser inundado, al igual que el área adyacente, cuando sobrevienen episodios torrenciales. A continuación, aguas abajo de la Fuente de la Teja, se extiende un tramo de cauce con márgenes recrecidos por motas de tierra, que tienen como fin evitar posibles inundaciones en los terrenos bajos colindantes (Figura 9).

El levantamiento de estas motas ha provocado la desconexión del cauce del río-rambla con su llano de inundación, modificando las condiciones de laminación de las avenidas, los aportes sedimentarios, la humedad edáfica y la cubierta vegetal. En la parte final del tramo aparece una vegetación densa dispuesta a modo de bosque de galería. A la altura del Molino de Diego de María, utilizado para derivar parte de agua del río hacia una acequia lateral, se produce una pérdida apreciable de caudal con la consiguiente deposición del material transportado y la alteración parcial de la morfología del lecho. La incorporación de aguas más claras en el extremo último del tramo origina una incisión local que avanza progresivamente hasta alcanzar una profundidad de más de 3 $m$ en un estrecho cauce encajonado y desaparecer con la apertura del encauzamiento artificial del tramo inferior (II3).

\subsubsection{Tramo inferior encauzado (II3)}

El tramo inferior, con $1.400 \mathrm{~m}$ de longitud, totalmente encauzado, tiene por objeto proteger al núcleo urbano de Vélez Rubio contra las inundaciones. Se trata de un encauzamiento de sección rectangular prismática, fondo no revestido y muros de hormigón. Con $8 \mathrm{~m}$ de anchura, 2,6 metros de altura, 3,7 \% de pendiente y un coeficiente de rugosidad medio de Manning en torno a 0,031, la capacidad máxima

ISSN: 0212-8594 ISSN-e: 2340-2776.№ DOI: http://dx.doi.org/10.12795/rea.2015.i32.07

REA 32 (2015):151-176

http://editorial.us.es/es/revista-de-estudios-andaluces 
Figura 9. Evolución de los tramos $\| 2$ y II3 entre 1956 y 2011 a partir de las fotografías aéreas de los vuelos USAF (1956), Comunidad Autónoma de Andalucía (CAA, 1981) y PNOA (2011).
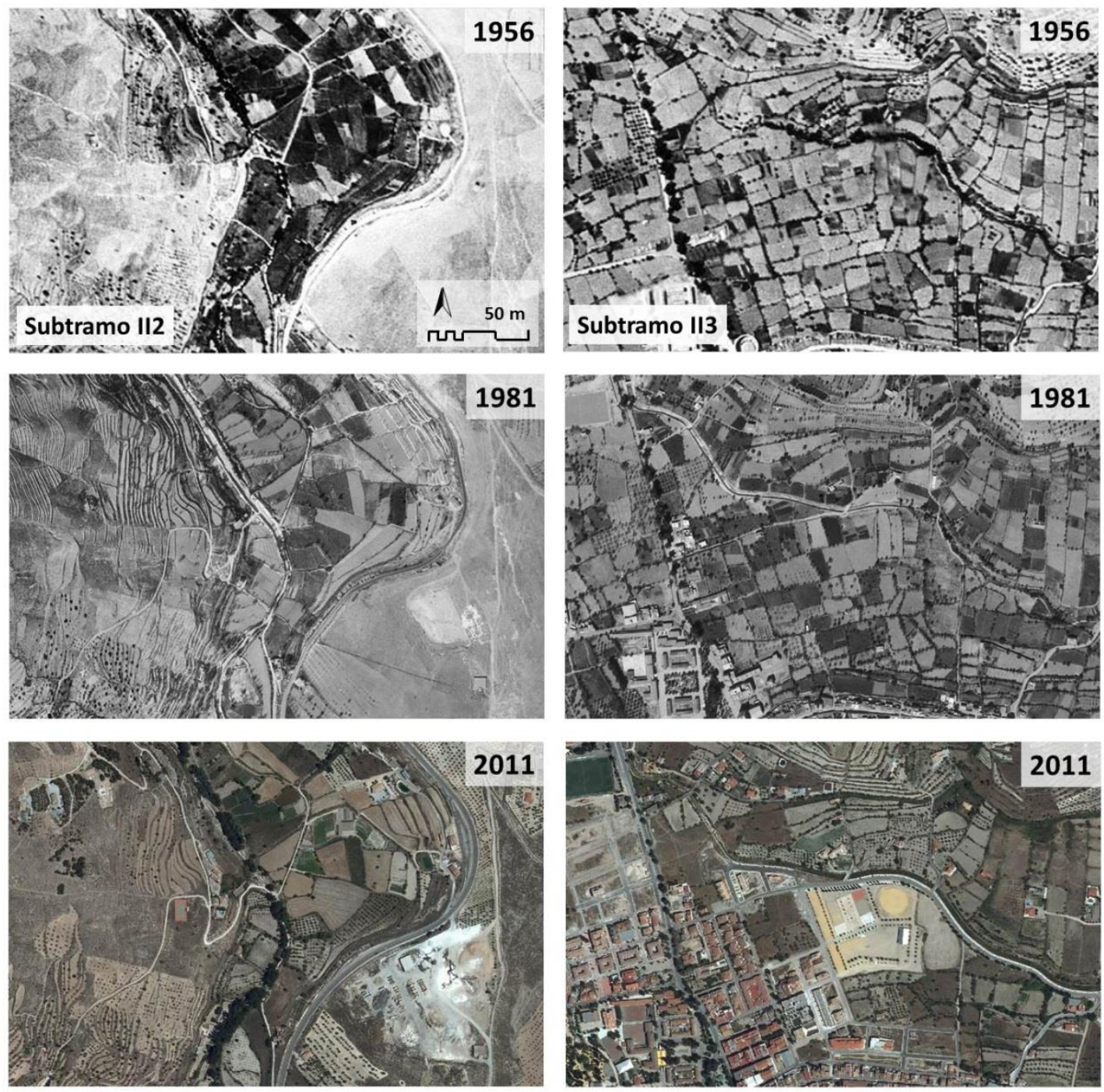

inicial de desagüe estimada para este tramo encauzado es de $174 \mathrm{~m}^{3} / \mathrm{s}$. No obstante, dicha capacidad hidráulica ha ido disminuyendo desde su construcción, debido al rápido ritmo de acreción sedimentaria del lecho fluvial, hasta situarse en torno a 142 $\mathrm{m}^{3} / \mathrm{s}$ en 2012. Los caudales calculados en este tramo por CHS - AYESA (2010) para tiempos de retorno de 100 y 500 años son de 75 y $111 \mathrm{~m}^{3} / \mathrm{s}$ respectivamente, por lo que sólo en grandes avenidas extraordinarias, con tiempo de retorno superiores, puede desbordar la corriente e inundar la zona norte de la población. Dicho encauzamiento desconecta el río respecto de la llanura de inundación provocando cambios significativos en sus niveles freáticos y régimen de humedad edáfica (CHS AYESA, 2010). 
El trazado de la obra presenta dos curvas con cierta inflexión en su tramo inicial, justo al norte de Vélez Rubio (figura 9). Ambas inflexiones, sin ser demasiado bruscas, aparecen de forma consecutiva en el inicio de dicho encauzamiento constituyendo los puntos de desbordamiento potencial más críticos. Especialmente peligrosos son los sectores cóncavos de su margen derecha, en los que las aguas de avenida pueden incidir con mayor fuerza, e incluso destruir la parte superior del muro protector. De desbordar en tales puntos la corriente, se producirían extensos lóbulos de derrame y grandes avalanchas de agua y material sólido (crevasse splays), que afectarían al citado núcleo. De hecho éste se localiza sobre un abanico aluvial que ha permanecido particularmente activo hasta la construcción del encauzamiento en 2002. También resta capacidad de desagüe a esta obra la existencia de una gruesa barra aluvial en la entrada misma del tramo encauzado. Mientras que este depósito, situado en la parte convexa de la primera curva, protege de forma temporal el muro de revestimiento izquierdo, la base del muro opuesto presenta claros síntomas de deterioro por su exposición directa a la trayectoria principal de los flujos de avenida (Figura 10a). Las obras transversales instaladas aquí consisten en pequeñas traviesas que terminan integrándose con la morfología del lecho al quedar casi enterradas, provocando ligeros ajustes, que disminuyen localmente la pendiente longitudinal del cauce.

Por otra parte, las secciones de drenaje de algunos de los puentes que atraviesan el río-rambla canalizado (el puente de la carretera A-317 y el puente peatonal, entre otros) muestran una importante pérdida de su capacidad inicial por causa de la acreción sedimentaria del lecho y de las obstrucciones que generan los arrastres sólidos (Figura 10b). La Confederación Hidrográfica del Segura llevó a cabo a mediados de 2013 una serie de actuaciones de acondicionamiento de este tramo, que básicamente consistieron en el dragado del lecho y limpieza de la vegetación en el mismo. Ante este tipo de intervenciones existen opiniones opuestas (Ollero et al., 2011), según las cuales se entiende que la llamada 'limpieza' de un río se basa en una visión primaria de éste como conducto y 'enemigo', sin tener en cuenta que con ello se modifica su propia dinámica morfo-sedimentaria y se rompe su equilibrio hidromorfológico longitudinal, transversal y vertical.

El tramo finaliza con netas marcas de erosión local en la zona de contacto entre la obra de encauzamiento y el lecho natural del río. El dragado del cauce en dicho tramo contribuye, sin duda, a acentuar la erosión progresiva del lecho aguas abajo del encauzamiento, al reducirse la carga sedimentaria de la corriente y no poder ser compensado el efecto de la erosión transitoria. 
Figura 10. (a) Estado del río Chico al inicio del encauzamiento; (b) Puente peatonal y vano con capacidad de drenaje mermada por la acreción sedimentaria del lecho.
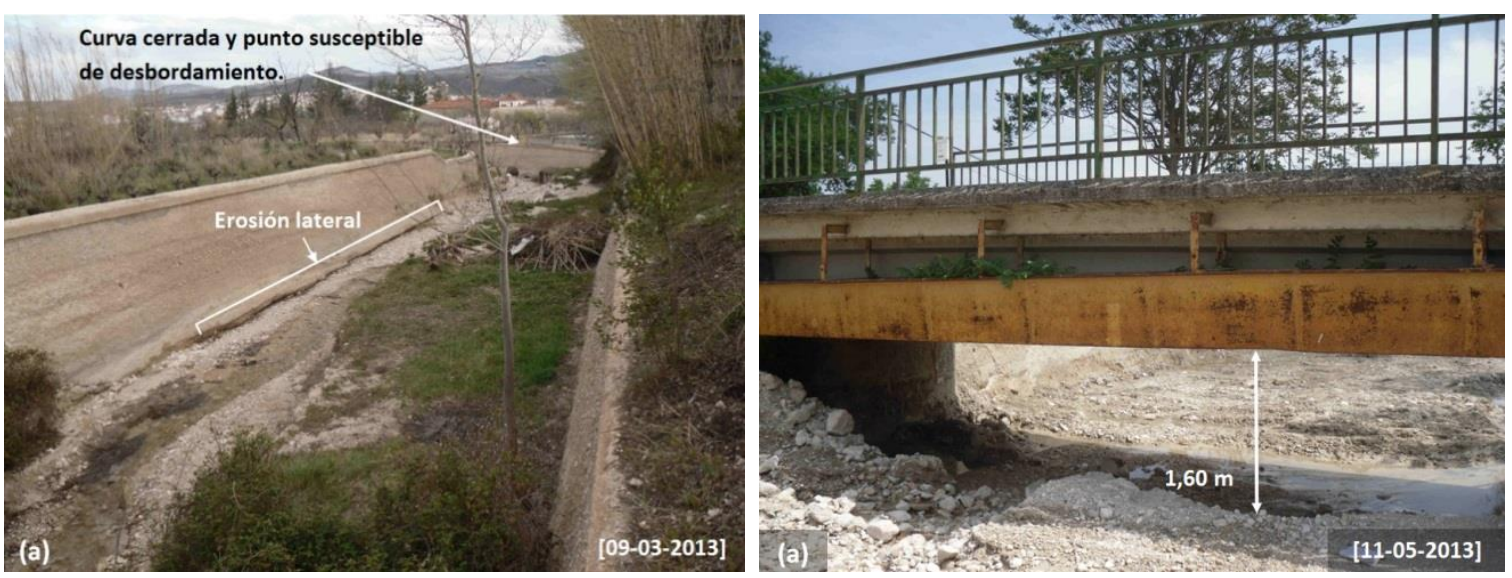

\section{DISCUSIÓN Y CONCLUSIONES.}

La intensa intervención antrópica sobre los sistemas fluviales mediterráneos de la Península Ibérica tiene su máximo exponente e impacto geomorfológico en las regiones de medio semiárido. Particularmente frágiles son los sistemas de drenaje efímero ante las actuaciones del hombre, cuyo impacto en las últimas décadas se ha dejado notar de forma muy significativa al alterar su equilibrio natural y deteriorar su calidad hidromorfológica (Conesa García, 2005). Claro ejemplo de ello lo constituye el río-rambla Chico, sometido a una intensa modificación de su régimen hidrológico y de su morfología. En este caso, como en otros muchos de la franja mediterránea (Camarasa y Segura, 2001; Conesa García y Pérez Cutillas, 2014), las actuaciones que afectan al medio fluvial obedecen a tres objetivos principales: 1 . Control de la erosión; 2. Prevención y protección contra inundaciones; y 3. Uso del lecho como vía de paso o acceso.

Para el control de la erosión se han llevado a cabo una serie de diques de retención de sedimentos y escolleras, que se localizan principalmente en la zona abarrancada de cabecera. Debido a la extraordinaria actividad geomorfológica de este tramo, dichas obras no siempre han sido efectivas, incluso han supuesto en muchos casos una profunda alteración de formas y procesos que afectan a todo el cauce, tanto longitudinal como transversalmente (variaciones locales de la pendiente, cambios bruscos en la geometría hidráulica, con ensanchamiento del cauce aguas arriba de los diques y encajamiento aguas abajo, rápidos ajustes del balance erosiónsedimentación, alternancia de cuñas sedimentarias y pozas de erosión, modificación apreciable de la carga de fondo y del transporte de sedimentos en suspensión, etc.). Efectos morfológicos similares han sido puestos de manifiesto por otros autores en cuencas torrenciales sometidas a una intensa corrección hidrológica (Martínez Castroviejo et al., 1990; Collier et al., 1996; Brandt, 2000; Grant et al., 2003; García-

ISSN: 0212-8594 ISSN-e: 2340-2776.N№ DOI: http://dx.doi.org/10.12795/rea.2015.i32.07 
Ruiz et al., 2010). En particular, las variaciones observadas en los niveles de bankfull antes y después de las fechas de construcción de los diques de retención han demostrado ser un excelente indicador para valorar el grado de encajamiento aguas abajo, derivado de las citadas obras (Conesa García y García Lorenzo, 2009). Claro ejemplo de ello lo constituye el nuevo cauce bankfull creado por este tipo de diques a lo largo del tramo analizado. El proceso de encajamiento sobre el antiguo lecho se inicia con la formación de una poza al pie de la estructura, cuyo desarrollo aparece agua abajo asociado a una lengua de derrame aluvial, compuesta por materiales procedentes de dicho excavado. Este hecho, ya constatado en numerosos casos (Comiti et al., 2005, 2010; Conesa-García y García-Lorenzo, 2010), tiene especial importancia en cauces con lechos de arenas y gravas, como el que caracteriza al alto río Chico. El lecho se hace inestable y no recupera su cota y perfil de equilibrio hasta que, una vez relleno el dique, se restablece de nuevo la continuidad longitudinal del transporte de fondo. La textura de los materiales del lecho ha sufrido también en este tramo cambios sustanciales, que afectan de forma notable a la rugosidad del cauce y a las condiciones hidrodinámicas de la corriente. Dicho parámetro deja de ejercer una influencia gradual en relación con la pendiente longitudinal del lecho para adoptar valores de fricción muy desiguales en función de la geoformas originadas por los diques. Algunas de estas estructuras, formadas por gaviones, han sido destruidas o muestran síntomas de rotura, socavamiento o erosión lateral, que le hacen perder estabilidad aumentando el riesgo de cambios morfológicos y sedimentarios bruscos en todo el tramo.

Aguas arriba de los diques la dinámica morfosedimentaria es bien diferente. A medida que aumenta su relleno, la pendiente local y general del cauce disminuyen, la capacidad de transporte de fondo también se reduce y los materiales gruesos tienen mayor dificultad para adentrarse en el vaso del dique. De esta forma, el modelo de sedimentación, tal como ocurre en otros cauces rectificados con fuerte carga tractiva (García-Ruiz et al., 2010), tiende a simplificarse desde la base al techo de la cuña sedimentaria, o lo que es lo mismo desde la fase inicial de relleno a la de colmatación. Las obras transversales de menor tamaño, traviesas o albarradas, presentan una mejor integración en el lecho, al que modifican ligeramente sin crear grandes alteraciones locales. En cambio, las obras longitudinales, diseñadas para la protección de los márgenes (escolleras y muros de revestimiento) afectan especialmente a los flujos sedimentarios y a los procesos de erosión lateral aguas abajo. Las escolleras laterales tienen también una importante presencia en el tramo alto del río-rambla, en el que persisten muchos de los rasgos propios del barranco de cabecera. Lo más común es que el constreñimiento de la dinámica lateral ocasionado por este tipo de estructuras provoque procesos de incisión en el lecho (Uribelarrea et al., 2003; Ollero, 2009). Sin embargo, en este tramo del río Chico el lecho muestra un fuerte acorazamiento superficial, debido a la presencia de abundante material grueso (gravas, cantos y bloques), y ello dificulta o impide la erosión vertical. En consecuencia, la energía de la corriente tiende a acumularse en dirección aguas abajo hasta el final del escollerado.

ISSN: 0212-8594 ISSN-e: 2340-2776.N№ DOI: http://dx.doi.org/10.12795/rea.2015.i32.07 
Una vez rebasado el segmento de escollera, la alta erosionabilidad de los materiales que componen los márgenes no revestidos, unido a la acción de un flujo localmente acelerado, producen efectos geomorfológicos drásticos, a menudo no deseables (rápido retroceso del margen, ensanchamiento local del cauce por erosión lateral, socavamiento de las estructuras, acción de zapa y despegue de los estribos de diques y traviesas). Tales efectos son potencialmente peligrosos cuando ponen en riesgo la estabilidad de puentes y carreteras.

En el tramo medio la principal alteración viene impuesta por la construcción de motas laterales que provocan una desconexión completa entre el cauce y la llanura de inundación. En el lecho se suceden largos surcos de incisión lineal con terrenos compactados por el paso de vehículos. Finalmente, el tramo final, encauzado en su totalidad, es el más desnaturalizado. El cauce ha perdido toda conectividad lateral, el nivel de base ha sido modificado, la pendiente incrementada y el lecho sufre una continua acreción sedimentaria vertical que obliga a realizar tareas de 'limpieza y mantenimiento'. En ausencia de tales actuaciones (diques, traviesas, escolleras, motas y encauzamiento) el río Chico dispondría de un mayor espacio fluvial, en el que podría desarrollar sus funciones hidrológicas y geomorfológicas, garantizando así la recuperación de sus valores naturales.

\section{Agradecimientos}

Este artículo ha sido realizado dentro del marco del proyecto de investigación $\mathrm{Pl} / 13$ "Respuesta hidrológica y geomorfológica a los sistemas fluviales torrenciales afectados por obras de restauración hidrológico-forestal en cuencas semiáridas del Sureste Peninsular", financiado por la Fundación Instituto Euromediterráneo de Hidrotecnia, Consejo Europeo y Comunidad Autónoma de la Región de Murcia.

\section{BIBLIOGRAFÍA}

Boix-Fayos, C.; Barberá, G.G.; López-Bermúdez, F.; Castillo, V.M. (2007): "Effects of check dams, reforestation and land-use changes on river channel morphology: Case study of the Rogativa catchment (Murcia, Spain)".Geomorphology 91: 103-123. http://dx.doi.org/10.1016/j.geomorph.2007.02.003

Bombino, G.; Boix-Fayos, C.; Gurnell, A.M.; Tamburino, V.; Zema, D.A.; Zimbone, S.M. (2014): "Check dam influence on vegetation species diversity in mountain torrents of the Mediterranean environment". Ecohydrology 7: 678-691. http://dx.doi.org/10.1002/eco.1389

Brandt, S.A. (2000): "Classification of geomorphological effects downstream of dams", Catena, 40: 375-401. http://dx.doi.org/10.1016/S0341-8162(00)00093-X

Bridge, J.S. (1993): "The interaction between channel geometry, water flow, sediment transport and deposition in braided rivers", In: Best, J.L., Bristow, C.S. (Eds.), Braided

ISSN: 0212-8594 ISSN-e: 2340-2776.№ DOI: http://dx.doi.org/10.12795/rea.2015.i32.07 
Rivers. Geol. Soc. Spec. Publ. 75 Geological Society, London 13-71p. http://dx.doi.org/10.1144/gsl.sp.1993.075.01.02

Brierley, G.J. and Fryirs, K.A. (2005): Geomorphology and river management. Applications of the River Styles Framework. Blackwell, Oxford, 398 p.

Camarasa, A.M. y Segura, F. (2001): "Las crecidas en ramblas valencianas mediterráneas". Estudios Geográficos, 62, 245: 649-674. http://dx.doi.org/10.3989/egeogr.2001.i245.270

Castillo, V.; Mosch, W.; González Barbera, G. y López Bermudez, F. (2001): "Efectos de los diques de corrección hidrológico-forestal en la geomorfología de barrancos y ramblas". III Congreso Forestal Español: 98-103.

Collier, M.P., Webb, R.H. y Schmidt J.C. (1996): Dams and Rivers. U.S. Geological Survey. Circular 1126, $94 \mathrm{p}$.

Comiti, F., Andreoli, A. and Lenzi, M.A. (2005): "Morphological effects of local scouring in step-pool streams". Earth Surface Processes and Landforms, 30(12): 15671581.http://dx.doi.org/10.1002/esp.1217

Comiti, F.; Lenzi, M.A. and Mao, L. (2010): Local scouring at check-dams in mountain rivers, in Conesa-García, C. \& Lenzi, M.A. (Eds.), Check Dams, Morphological Adjustments and Erosion Control in Torrential Streams. Chapter 12, Nova Science Publishers, New York, pp. 261-282.

Conesa García, C. y Pérez Cutillas, P. (2014): "La reciente alteración geomorfológica de los sistemas fluviales mediterráneos en la Península Ibérica. Síntomas y problemas de incisión del cauce". Revista de Geografía Norte Grande. 59: 25-44. http://dx.doi.org/10.4067/S0718-34022014000300003

Conesa García, C. y García Lorenzo, R. (2007): Erosión y diques de retención en la Cuenca Mediterránea. Fundación Instituto Euromediterráneo del Agua, Murcia, 669p.

Conesa García, C. y García Lorenzo, R. (2009): Bankfull hydraulic geometry adjustments caused by check dams in ephemeral channels (South-East Spain, Western Mediterranean). In Hayes, W.P. \& Barnes, M.C. (Eds.): Dams: Impacts, Stability and Design. Nova Science Publishers, Inc. New York. pp. 75-99.

Conesa-García, C. and García-Lorenzo, R. (2010): Bed scour-sedimentation balance induced by check dams in semiarid catchments with different lithology, in ConesaGarcía, C. \& Lenzi, M.A. (Eds.), Check Dams, Morphological Adjustments and Erosion Control in Torrential Streams. Chapter 13, Nova Science Publishers, New York, pp. 283306.

ISSN: 0212-8594 ISSN-e: 2340-2776.№ DOI: http://dx.doi.org/10.12795/rea.2015.i32.07 
Conesa García, C. y García Lorenzo, R. (2011): “Factores e Índices de Peligrosidad de las aguas de avenida en cruces de carreteras con ramblas. Estudio aplicado a la vertiente litoral sur de la Región de Murcia". Boletín de la Asociación de Geógrafos Españoles, 57: 198-215.

Conesa García, C. y Pérez Cutillas, P. (2014): “La reciente alteración geomorfológica de los sistemas fluviales mediterráneos en la Península Ibérica. Síntomas y problemas de incisión del cauce". Revista de Geografía Norte Grande. 59: 25-44.

Confederación Hidrográfica del Segura (CHS) (2008): Manual para la Restauración de riberas en la cuenca del río Segura, Murcia, 230p.

Confederación Hidrográfica del Segura (CHS) - AYESA (2010): Valoración del Estado Ambiental del río Chico. Confederación Hidrográfica del Segura, 33p.

Csiki, S. and Rhoads, B.L. (2010) "Hydraulic and geomorphological effects of run-ofriver dams". Progress in Physical Geography, 34, 6: 755-780. http://dx.doi.org/10.1177/0309133310369435

Diaz del Olmo, F. (1986) "El tratamiento de los elementos abióticos en la planificación territorial". Revista de Estudios Andaluces, 7.

Elliott, E.T. (1986): "Aggregate structure and carbon, nitrogen, and phosphorus in native and cultivated soils". Soil Sci. Soc. Am. J. 50: 627-633. http://dx.doi.org/10.2136/sssaj1986.03615995005000030017x

Fuchu, D.; Lee, C.F. and Sijing, W. (1999): "Analysis of rainstorm-induced slide-debris flows on natural terrain of Lantau Island, Hong Kong". Engineering Geology, 51 (4): 279-290. http://dx.doi.org/10.1016/S0013-7952(98)00047-7

García-Ruiz, J.M., Alatorre, L.C.; Gómez-Villar, A. and Beguería, S. (2010): Upstream and downstream effects of check dams in braided rivers, Central Pyrenees, in Conesa García, C. \& Lenzi, M.A. (Eds.), Check Dams, Morphological Adjustments and Erosion Control in Torrential Streams. Chapter 14, Nova Science Publishers, New York, pp. 307-326.

González Del Tánago, M. y García De Jalón, D. (1998): Restauración de Ríos y Riberas. ETSIM, Madrid, 65p.

Grant, G.E., Schmidt, J.C. and Lewis, S.L. (2003): "A Geological Framework for Interpreting Downstream Effects of Dams on Rivers". Water Science and Application. American Geophysical Union, 7: 209-225.http://dx.doi.org/10.1029/007ws13

López Bermúdez, F.; Conesa García, C. and Alonso Sarría, F. (1998): "Ramblas y barrancos mediterráneos: medio natural y respuesta humana", Mediterrâneo Desertificaçao, 12/13: 223-242.

ISSN: 0212-8594 ISSN-e: 2340-2776.№ DOI: http://dx.doi.org/10.12795/rea.2015.i32.07 
Martín Rosales W.; Pulido Bosch A. y Vallejos A. (1995): “Mecanismos generadores de escorrentía en la vertiente de Sierra de Gádor (Almería)". Geogaceta 18: 134-137.

Martínez Castroviejo, R., Inbar, M., Gómez Villar, A. y García Ruiz, J.M. (1990): Cambio en el cauce aguas abajo de una presa de retención de sedimentos. I Reunion nacional de Geomorfología, Teruel. pp. 457-468.

Mintegui Aguirre J.A.; De Simón Navarrete E.; García Rodríguez J.L. y Robredo Sánchez J.C. (1993): La restauración hidrológico-forestal en las cuencas hidrográficas de la vertiente mediterránea. Informaciones Técnicas 22/93, Consejería de Agricultura y Pesca de la Junta de Andalucía, Sevilla, 325p.

Ollero Ojeda, A. (2009): Aplicación del índice hidrogeomorfológico IHG en la cuenca del Ebro. Guía metodológica. Confederación hidrográfica del Ebro, Zaragoza, 91p.

Ollero, A.; Ibisate, A.; González De Matauco, V.; Naverac, A.; Díaz, E.; Granado, D. y García, J. H. (2011) Innovación y libertad fluvial. VII Congreso Ibérico sobre Gestión y Planificación del Agua "Ríos Ibéricos +10. Mirando al futuro tras 10 años de DMA", Talavera de la Reina, 2011, 4-14.

Prosser, I.P.; Rutherfurd, I.D.; Olley, J.M.; Young, W.J.; Wallbrink, P.J.; Moran, C.J. (2002): "Large-scale patterns of erosion and sediment transport in river networks, with examples from Australia". Marine and Freshwater Research, 52: Pages 81-99. http://dx.doi.org/10.1071/MF00033

Sundborg, Å. (1956): "The river Klarälven: a study of fluvial processes", Geografiska Annaler, 38A: 127-316.

Terzaghi, K. and Peck, R. B. (1948): Soil Mechanics in Engineering Practice. Ed. John Wiley and Sons, New York, 566p.

Thorne, C.R.; Red S. and Doornkamp, J.C. (1996): A procedure for Assessing River Bank Erosion. Problems and Solutions. R\&D Report 28, National Rivers Authority, Bristol, U.K. Tockner, K. and Stanford, J.A. (2002): "Riverine flood plains: present state and future trends", Environmental Conservation, 308-330. http://dx.doi.org/10.1017/S037689290200022X

Trask, P.D. (1950): Applied sedimentation. John Wile and Sons Inc, New York. 707 p. http://dx.doi.org/10.5962/bhl.title.16378

Uribelarrea, D.; Pérez-González, A. and Benito, G. (2003): "Channel changes in the Jarama and Tagus rivers (central Spain) over the past 500 years". Quaternary Science Reviews, 22: 2209-2221. http://dx.doi.org/10.1016/S0277-3791(03)00153-7 
Varela Nieto, J.M. (Dir) (1999): Inventario de obras de corrección hidrológica-forestal y de las variables ambientales relacionadas con las mismas. Centro de Estudios de Técnicas Aplicadas. Dirección General de Obras Hidráulicas.

VV.AA. (2010): Restauración de Ríos: Bases de la estrategia nacional de restauración de ríos. Ministerio de Medio Ambiente y Medio Rural y Marino, 27p.

Zema, D.A.; Bombino, G.; Boix-Fayos, C.; Tamburino, V.; Zimbone, S.M.; Fortugno, D. (2014): "Evaluation and modeling of scouring and sedimentation around check dams in a Mediterranean torrent in Calabria, Italy". Journal of Soil and Water Conservation 69: 316-329. http://dx.doi.org/10.2489/jswc.69.4.316 